\title{
THE FEASIBILITY OF “OSCAR” AS AN INFORMATION SYSTEM FOR SUSTAINABLE REHABILITATION OF BUILT HERITAGE
}

\author{
C. Farmer ${ }^{\mathrm{a}}$, C. Rouillard ${ }^{\mathrm{b}-*}$ \\ a Azrieli School of Architecture, Carleton University, 1125 Colonel By Drive, Ottawa, Canada, K1S 5B6- carly.farmer@outlook.com \\ b Jan Hird Pokorny Associates, Inc., 39 West 37th Street, Suite 12A, New York, United States, 10018 - rouillard@ jhpokorny.com
}

\author{
Commission II, WG VI/4
}

KEY WORDS: Information Systems, Web Application, Sustainable Design, Heritage Conservation, Retrofit

\begin{abstract}
:
This paper aims to examine the feasibility of the Online Sustainable Conservation Assistance Resource (OSCAR) as an information system and framework to help find appropriate ways to improve the sustainable performance of heritage buildings in North America. The paper reviews the need for holistic comprehensive authoritative information in the field of sustainable conservation, how OSCAR addresses this gap, the OSCAR workflow, and how it was used in two case studies. It was found that OSCAR has potential to become a practical educational tool and design aide to address the sustainable performance of heritage buildings. The paper contributes to the discourse on sustainable conservation by examining resources and tools which address the need for holistic retrofit approaches. The findings will be useful to educators and professionals in the fields of sustainable design and heritage conservation.
\end{abstract}

\section{WHY OSCAR}

\subsection{Improve sustainable performance \& fight climate change}

The Online Sustainable Conservation Assistance Resource (OSCAR) (1) is an information system designed to guide sustainable retrofits of heritage buildings in a way which is compatible with the character, values, materials and components. It is developed by the Association for Preservation Technology International (APTI) Technical Committee for Sustainable Preservation (TC-SP).

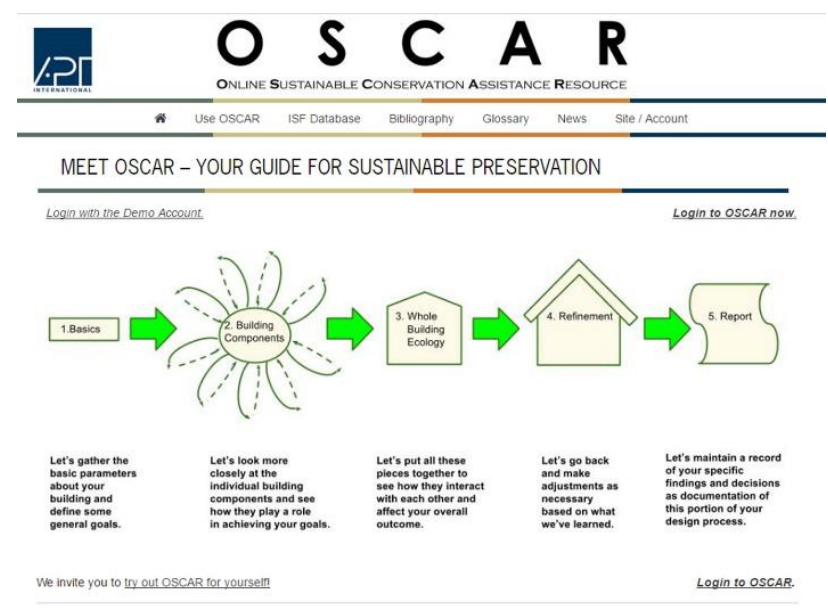

Figure 1. OSCAR 1.0 home page

In order to ensure a sustainable and resilient future which limits the impacts of climate change, governments, organizations and individuals are demanding more stringent standards in sustainable performance for both new and existing buildings. Consequently, there is increasing pressure for heritage buildings to meet these standards, prompting an increase in sustainable retrofits - for better and for worse.

Buildings constructed before the middle of the twentieth century use different energy efficiency strategies than today's new buildings. Furthermore, mid-century modern buildings were often experimental in their use of materials and assemblies. Therefore, the most effective sustainable retrofits require special consideration of the building envelope and inherently sustainable features.

\subsection{Disseminate authoritative information}

Although many academics and professionals have researched the synergies between heritage conservation and sustainability, this information is relatively inaccessible, especially to those who are less familiar with this topic. Navigation of resources is further complicated by the fact that strategies which are successful in one climate or context may be harmful in another. Furthermore, existing research often only deals with two or three components/variables rather than the holistic approach demanded by complex sustainable conservation projects. All these factors contribute to debates and misunderstandings within and between the academic community, working professionals and their clients. Misunderstandings often result in interventions which either have adverse impacts to heritage values, or are less effective than they otherwise could have been.

To illustrate one area of debate, green building design assessment systems (for example LEED, Green Globes, etc.) are generally based on standards written for new buildings and thus seldom equipped to consider materials and assemblies used in heritage buildings. These systems often focus on reducing operating energy, and while this is important, the most sustainable decision will come through careful consideration of many factors throughout the life-cycle (such as embodied energy, pollution, durability, reparability, etc.). (Powter and Ross, 2005) For

\footnotetext{
* Corresponding author
}

(1) www.oscar-apti.org 
example, "Research into the Thermal Performance of Traditional Windows: Timber Sash Windows" published by Historic England in 2009 demonstrates that traditional wood framed windows can obtain comparable performance to advanced modern designs through repair, refurbishment and use of curtains or blinds (Historic England, 2009). To emphasize the need for a holistic approach, note that improved heat retention can potentially lead to condensation issues depending on factors such as humidity levels and climatic conditions.

\section{CONTEXT}

\subsection{History of OSCAR}

The APTI Technical Committee for Sustainable Preservation created OSCAR to address the gap of how to integrate new and existing research in technologies and processes for sustainable design and heritage conservation into an accessible and comprehensive web application. This interactive resource establishes a clear process to aid in making optimal decisions for the sustainable rehabilitation of heritage buildings.

Development of OSCAR version 1.0 began in 2011. It was officially released in 2015 and tested in 2016, at which point work on OSCAR 2.0 commenced.

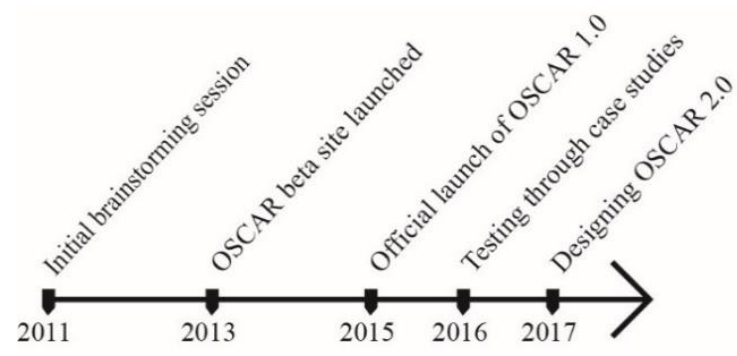

Figure 2. Timeline of OSCAR's development

\subsection{Who is OSCAR for?}

In the architecture, engineering and construction industry, there is a subset of professionals who are specialized in sustainable design and another subset of professionals who are specialized in heritage conservation. Additionally, there are many more professionals with expertise in neither and comparatively very few who have expertise in how the two areas work together. OSCAR is intended to assist industry professionals (regardless of their level of expertise) with sustainable rehabilitation of existing buildings.

OSCAR is also designed to be an excellent learning tool for students and academics in related disciplines. Furthermore, the clear simple language and illustrations keep the content relevant to a much broader audience of building owners and managers and others outside of the field.

\subsection{Scope of OSCAR}

In the initial versions of OSCAR, the content is primarily focused on building technologies and climate types within North America, from the arctic to the tropics. Since this covers a great diversity of climates and strategies, much of the content would be applicable to other geographical regions as well. Additionally, the Inherently Sustainable Features (ISF) database documents design traditions from across the globe. All content is written in English; however, future versions could potentially be translated into multiple languages.
OSCAR was created primarily for academics and professionals within the building and construction industry. The intent is to provide basic information in small, easily 'digestible' quantities and reference users to other authoritative resources for further investigation. Because of its emphasis on understanding and conserving values, OSCAR is relevant for work on all existing buildings, whether or not they are recognized as heritage.

\subsection{Precedent Analysis}

Upon review of other online information systems, these three are most similar to OSCAR in level of utility. To varying degrees, they also seek to address the complex issues of creating a sustainable built environment.

The Sustainable Traditional Building Alliance created the "Guidance Wheel" to aid decision making and learn about the retrofit of traditional buildings (pre-1919) in the United Kingdom. (Sustainable Traditional Buildings Alliance, 2012). Similar to OSCAR, it addresses challenges of the uncertainty of existing data and research, complex interactions, and potentially conflicting priorities and values. Users select interventions of interest to see benefits, concerns, interrelationships with other interventions, and references to relevant and accurate information from the STBA Knowledge Centre. The result is a report of systematic and holistic approaches to design, application and use of sustainable retrofits. In contrast to the Guidance Wheel, OSCAR considers the wide range of climates, materials and typologies across North America, including modern heritage. (Sustainable Traditional Buildings Alliance, "Guidance Wheel." n.d.)

2030 Palette provides architects and planners guidance on designing low-carbon and adaptable built environments. The web application looks at strategies which occur globally at a range of scales: region, city/town, district, site, and building. Although many of the strategies are inherently sustainable features in historic districts and buildings, 2030 Palette provides little to no guidance on working in a historic context since it is intended to assist with new construction and building the "next built environment." In comparison with 2030 Palette, OSCAR looks at the smaller scales of building, component, and materials for existing buildings. While the 2030 Palette is well-aligned with the goals of OSCAR, there is very little overlap. (Architecture 2030, n.d.)

InspectAPedia.com is a free online encyclopedia of building and environmental inspection, testing, diagnosis and repair. Articles and how-to guides are comprehensive in scope and cover a wide breadth of components and topics such as energy efficiency, occupant health, and how to determine the age of a building. Although content is not subjected to a scholarly peer review process, all content is technically reviewed, edited, and subject to a wide public exposure peer review process for accuracy and absence of bias. While there is little emphasis on heritage conservation and related best practices (such as minimum intervention), the articles promote repair and maintenance of historic and modern materials and assemblies. (InspectAPedia.com, n.d.)

\section{WHAT IS OSCAR?}

OSCAR is an information management system for best practice for retrofitting heritage buildings or building components. APTI created OSCAR to address the gap of how to integrate new and existing research in technologies and processes for sustainable design and heritage conservation into an accessible and 
comprehensive web application. This interactive resource establishes a clear process to aid in making optimal decisions for the sustainable rehabilitation of heritage buildings.

OSCAR provides practical guidance following a structured framework for repair and rehabilitation treatments for every individual building component and its relationship to the whole building ecology (2). It also contains a living (i.e. on-going updates) bibliography of reputable resources regarding the intersection of heritage and sustainability.

\section{WHEN TO USE OSCAR}

OSCAR's main purpose is to address the question of how to improve the sustainable performance of an existing building in a way that is appropriate to its heritage values. Table 1 illustrates the ten categories of sustainable performance addressed by OSCAR

\begin{tabular}{|l|l|}
\hline Operational & Lifecycle \\
Performance & Performance \\
\hline Air-tightness & Durability \\
Ventilation & Ease of Maintenance \\
Thermal Mass & Embodied Energy \\
Insulation & End of Life Disposal \\
Solar Heat Gain & \\
Daylighting & \\
\hline
\end{tabular}

Table 1. Ten categories of sustainable performance

First and foremost, OSCAR is designed to disseminate research and practical guidance for repair and retrofit of heritage buildings. It is a reference to be used throughout the design process with emphasis on diagnosis, therapy and interventions to improve energy performance. A basic analysis or description of each intervention or "Action" is followed by links to resources for more in depth investigation.

\section{HOW TO USE OSCAR}

OSCAR functions as a repository of good, peer-reviewed (3), reputable information which can be accessed in two different ways, through the "References" or via the "Project Builder."

\subsection{Reference Databases}

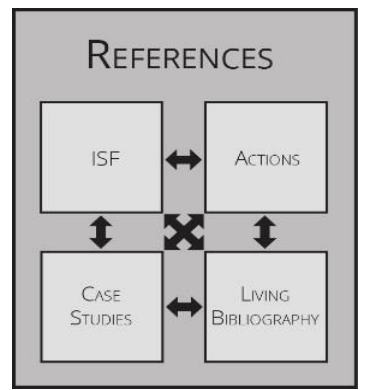

Figure 3. Interconnectivity between reference databases

(2) Whole Building Ecology is defined as the "comprehensive understanding of the building's original materials and assemblies, including interrelated systems, materials sourcing, design language, and spatial organizations." (Federal Provincial Territorial Historic Places Collaboration, 2016)
The References section consists of a series of databases of readily accessible information for quick browsing and learning. The interrelationships between each entry topic are expressed through links to "related topics" within any of the four databases.

\subsubsection{Inherently Sustainable Features}

Traditionally, buildings had energy-efficient features out of necessity. Application of the basic principles of thermodynamics resulted in a diversity of features, many of which became character-defining features of specific buildings and or local building traditions. By recognizing inherent energy-harnessing features and systems and how they function, the rehabilitation strategy can work with (rather than against) the historic design intent. This also helps to prioritize work, including the reconstruction of non-extant original features which support the sustainability goals. The Inherently Sustainable Features (or ISF) database sorts through many techniques from a variety of climates and traditions from around the world to foster awareness and stay attuned to opportunities to use such strategies where appropriate. In OSCAR 1.0, features can be filtered according to climate, component, intent, or theory. (OSCAR, n.d.)

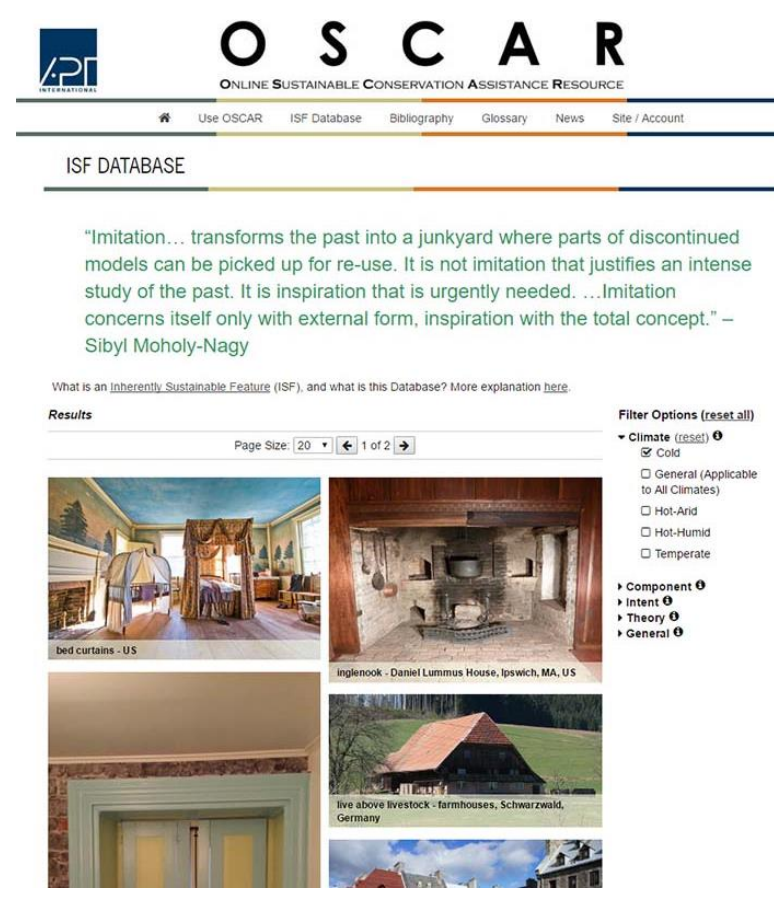

Figure 4. ISF database in OSCAR 1.0

\subsubsection{Actions}

There are many different actions that can be taken to improve the sustainable performance of buildings. Preservation (4) Actions focus on repair and maintenance of components to extend service life and or improve operational effectiveness. For example, what is an appropriate intervention for a corroded steel sash window? Much of this is typical for heritage professionals and follows international standards for best practice (i.e. Venice Charter, etc.).

(3) All content produced by APTI is internally reviewed to ensure accuracy and consistency.

(4) Preservation is the general term for heritage conservation in the United States of America. In OSCAR, the term preservation also encompasses treatments of restoration and rehabilitation. Outside the USA, these three treatments in general often fall under the umbrella term "Conservation." 
Assuming every component of the entire building is in perfect condition, there may be other appropriate ways to further improve energy efficiency and overall performance. Energy Actions might include a natural ventilation strategy, adding weatherstripping or insulating the attic.

Each Preservation and Energy Action briefly addresses the questions of: what; why; how; concerns; sustainability considerations; and climate considerations. Additionally, each Action is rated for its contribution (none, somewhat, excellent and caution required) to sustainable performance in each of the ten categories identified in Table 1. Furthermore, there are links to authoritative references in the Bibliography for further reading on that topic.

\subsubsection{Case Studies}

The Case Studies database unites these three databases by showcasing good examples of sustainable rehabilitation projects from around the world and interrelationships between components and interventions. Case studies are cross-referenced according to climate type, location/country, building type, ISFs, preservation actions, sustainable interventions, and goals and priorities so they can be easily filtered. The Case Studies database is still in development and will be part of OSCAR 2.0.

\subsubsection{Bibliography}

Finally, the living Bibliography contains over 800 reference items on the topic of sustainable conservation. Only references which are deemed authoritative are included, such as those which are peer reviewed or from reputable institutions in the field. Reference items include everything which is cited on OSCAR as well as related items of interest to the APTI Technical Committee on Sustainable Preservation such as the connections between climate change and conservation. The Bibliography is created using Zotero, an open source reference management program, which is integrated to the OSCAR website.

\subsection{Project Builder}

In OSCAR 2.0, the Project Builder (5) is the framework for decision-making with regards to a specific building. This function requires users to create a free account and log-in so that user-inputted data and reports can be saved for future reference. The Project Builder is broken down into four steps: Building Profile; Component Manager; Collections; and Report.

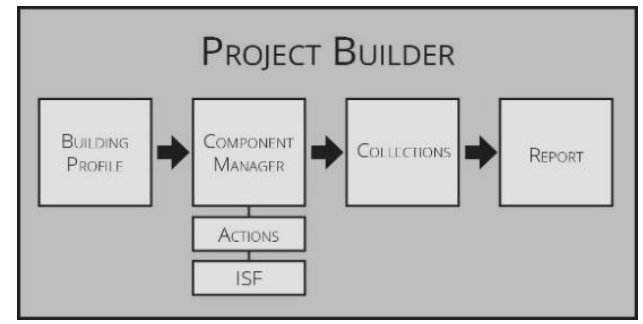

Figure 5. Project Builder sequence

\subsubsection{Building Profile}

The Building Profile" establishes the context of the project. Users input: the location of the building; the climate type; building size;

(5) The four-step Project Builder is an enhanced version of the five-step process of OSCAR 1.0. The "Refinement" step in OSCAR 1.0 has been removed because it was found to be redundant. The remaining steps of OSCAR 1.0 (Basics, Components, Whole Building Ecology, and Report) roughly building age; code compliance; preservation goals; historical significance; character-defining features; energy and comfort systems; and energy goals. Users also prioritize which sustainable performance categories (as illustrated in Table 1) they would like to focus on. In addition to increasing awareness between building performance and these contextual factors, some information in this section will be integrated with other aspects of the Project Builder. For example, the Character-Defining Features Master List is incorporated into the ISF Actions page.

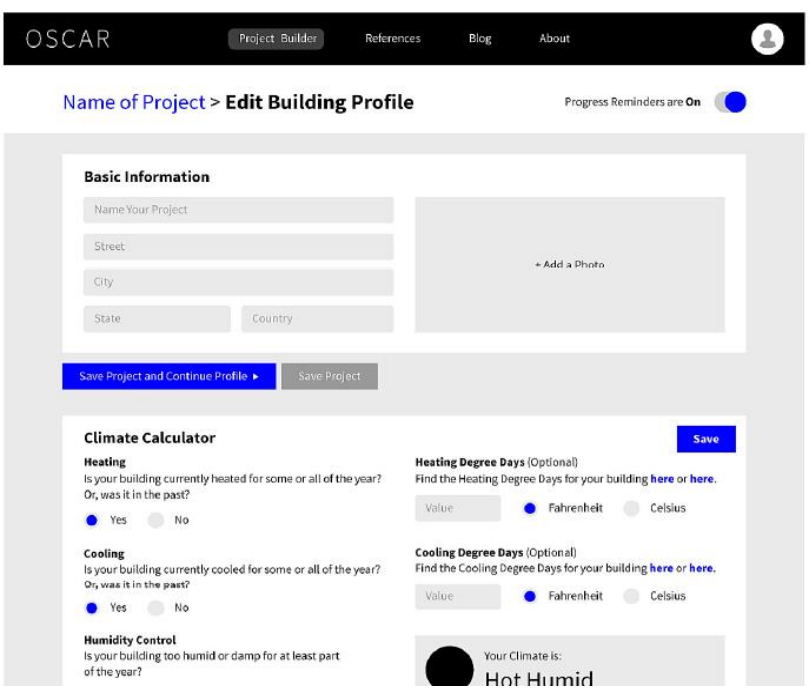

Figure 6. Building Profile wireframe (preliminary) mock-up

\subsubsection{Component Manager}

The Component Manager is where the building is broken down into its individual components where they can be studied in isolation. Users can identify all the variations of component types (attic, basement, interior layout, roof, site, systems, walls and windows) which are relevant to the project. Users have the option to upload their own photos of the building's components and write their own comments. Within each component type, users can access related entries from the ISF, Preservation and Energy Actions databases to learn more about how to improve the sustainable performance of that particular component. Relevant Actions can be saved to a Collection.

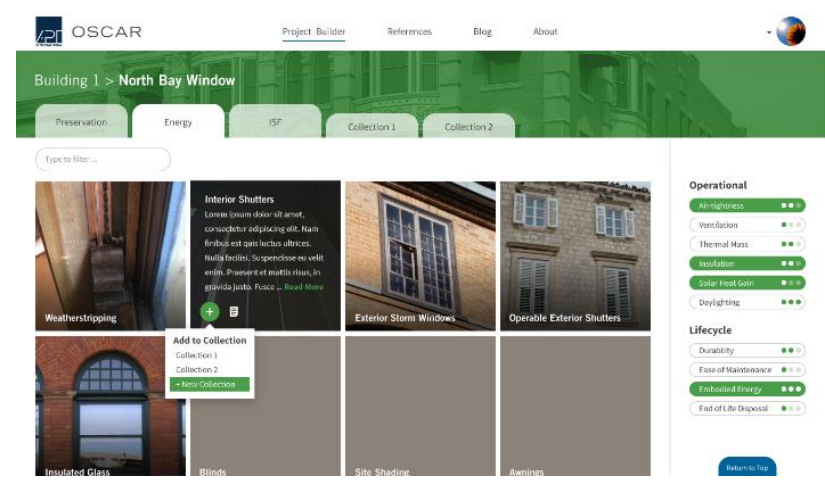

Figure 7. Component Manager high definition mock-up

correspond with the OSCAR 2.0 titles (Building Profile; Component Manager; Collections; and Report). Section 5.2 focuses on the functionality of the Project Builder as it will appear in OSCAR 2.0 while section 6 focuses on OSCAR 1.0 as it was used in the case studies. 


\subsubsection{Collections}

This step looks at how different Collections or combinations of Actions can be applied to a component according to user-defined scenarios. A component may have multiple Collections for quick comparison and to determine which options best meet priorities of the project. For example, one Collection could prioritize maximizing operational energy efficiency, while another Collection might focus on minimizing capital costs.

\subsubsection{Report}

The user generates whole building strategy Reports by selecting one Collection for each identified component. The interrelationships between components are made visible, as the Actions are then sortable by sustainable performance category. (For example, the insulation strategy for each component may be viewed together to understand this envelope improvement as a whole.) Each Report, which also includes summary information for each Action, may be saved in a printable format.

\section{EFFECTIVENESS}

The usefulness of OSCAR version 1.0 was tested through two case studies. The first demonstrated how OSCAR could be used by professors as an educational tool. For the second case study, an architecture firm applied the Project Builder framework to a building.

\subsection{OSCAR as a teaching tool}

The first "academic" case study demonstrates how OSCAR could be used by professors as an educational tool. Carleton University in Ottawa, Canada was selected because of its conservation and sustainability programs in architecture and engineering and the significant contributions of its students to the development of OSCAR. Architecture and engineering students in the final year of the undergraduate program are required to take a course on "Building Pathology and Rehabilitation."(6) The essay assignment was restructured to better align with the format of the OSCAR. This increased awareness and familiarization of the web application as an important resource for sustainable rehabilitation of the building envelope, one of the core objectives of the class. Students were required to: select a component; identify and explain how to repair pathological conditions (for example, corrosion); and also analyse interventions to further enhance operational or life-cycle efficiency (for example, provide storm windows).

\subsection{OSCAR as a professional practice tool}

For the "professional" case study, MTBA Associates Inc. (a small architecture, urbanism, and conservation firm in Ottawa, Canada) provided the building owners with a pro-bono analysis for the mid-century modern Ottawa East Seventh Day Adventist (SDA) Church (7). The client is preparing to expand the facility with more programs to accommodate the growing congregation. The client also wants to be a good steward and was advised to understand the building that they have now and how to improve its sustainable performance so as not to adversely impact its unique character. This investigation used the OSCAR 1.0 version of the Project Builder framework to develop recommendations for repair and upgrades which would yield the greatest overall improvement in sustainability.

(6) Author Carly Farmer was the teaching assistant of this class

\subsubsection{Building Profile (Basics)}

The Ottawa East Seventh Day Adventist (SDA) Church is a unique demonstration of the ideas of celebrated local architect James Strutt. It is characterized by two steeply pitched hipped roofs which seem to float above a continuous ring of clerestory windows. The rabbeted windows display an innovative use of traditional materials and conceal steel columns supporting the roof. With frontage on two streets, the property is also an important passage for pedestrians and cyclists in the neighbourhood. Priorities in sustainable performance include: durability of materials; natural ventilation; air-tightness; and insulation.

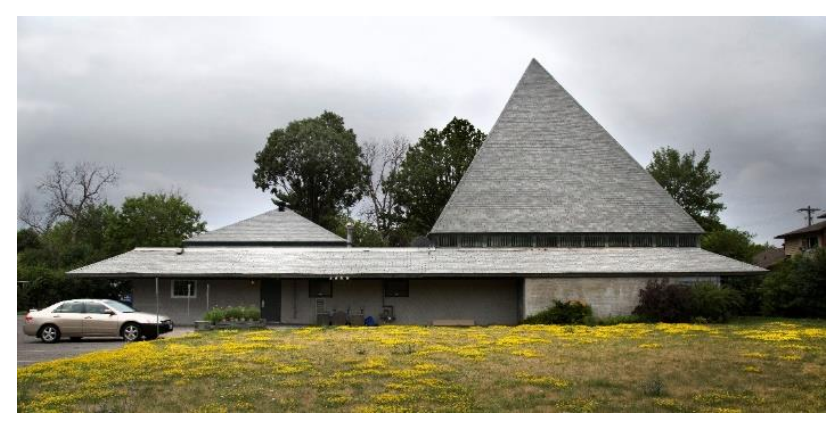

Figure 8. Ottawa East SDA south facade

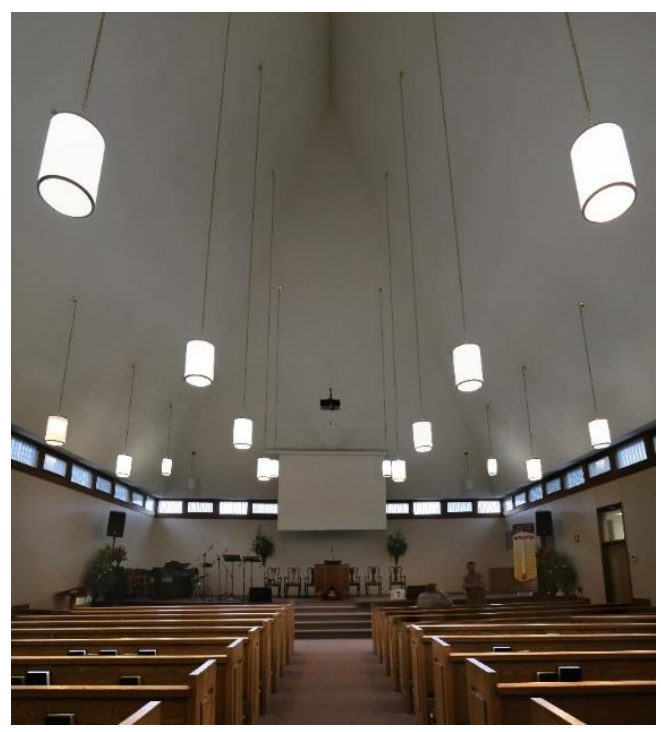

Figure 9. Ottawa East SDA sanctuary

\subsubsection{Component Manager}

Inherently Sustainable Features which contribute to the character of the building include: large perimeter roof overhangs to protect building facades; steep hipped roofs to shed snow and rain; "operable" clerestory wood windows with grilles to reduce glare; location in a dense residential neighbourhood.

Recommended Actions for the clerestory windows include: painting to improve durability; restoring operability to improve ventilation; replacing broken glass to improve air-tightness; and adding weatherstripping to improve air-tightness; and adding interior storm windows to improve insulation and air-tightness. 


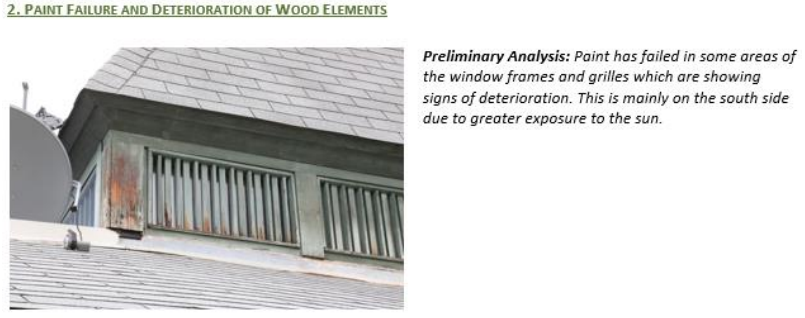

What: The window frame is a fixed element, consisting of two jambs (at the sides), a head (at the top), and a sill (at the bottom). Maintaining a paint layer protects the wood from moisture and increases its service life.

Why: Wood decay can result from moisture trapped due to heavy paint buildup ${ }^{83}$, flaking or failed paint. Paint peeling down to bare wood is a clear indication of trapped moisture ${ }^{39}$. In general, there are documented longterm embodied energy savings and greater overall energy efficiency, when window frames are repaired, rather than replaced.

How: To repair wood elements:

- Remove sashes if necessary.

- Scrape loose paint prior to are ceveral laverc nf naint

Figure 10. Action for paint failure on clerestory windows

\subsubsection{Collections (Whole Building Ecology)}

The architecture firm took a slightly different approach to the Collections step than was originally intended for OSCAR 1.0. Rather than comparing Collections of Actions, this case study analysed the interrelationships between the components and what interventions would yield the greatest overall improvement in the prioritized sustainable performance categories.

For example, a passive cooling and ventilation strategy was developed rather than upgrading the poorly functioning energy intensive air conditioning. As illustrated in Figure 11, this could be done by: a) restoring original design intent by making the windows operable; b) enhancing this design with fans; or c) doing all of this and venting air out the peak of the roofs to take advantage of stack effect. The fans will also improve heating efficiency in winter by pushing warm air down to the inhabited areas.
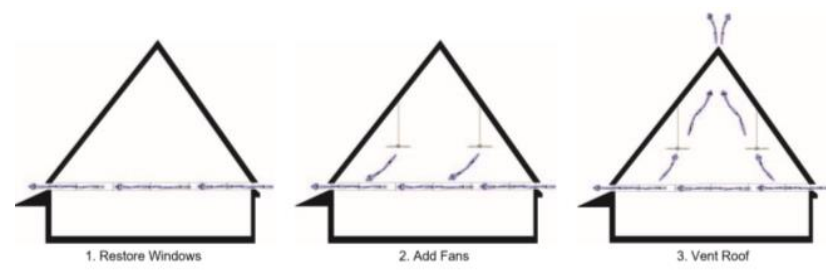

Figure 11. Ventilation strategy

\subsubsection{Report}

At the time of the project (summer 2016), OSCAR 1.0 was very limited in content and therefore the automatic report feature was not online. However, the information available on OSCAR and draft content (pending peer review) was copied into a new document and presented in a manner similar to the report that OSCAR would generate as shown in Figure 10.

\section{CONCLUSION}

\subsection{Feedback}

The general opinion among students, colleagues and conference delegates is that OSCAR has potential to assist by simplifying and explaining the process one needs to go through to find sustainable retrofit solutions which maintain the buildings' heritage values. Bringing OSCAR into the classroom generated much interest as evidenced with at least 6 students making significant contributions to its development.

After testing out the OSCAR process at MTBA Associates, Inc., Principal Architect Mark Brandt observed that OSCAR helped the office to have a standard way of breaking down complex issues. Additionally, the interns working on the case study found the process of looking at the context, the individual components and then the interrelationships to be an effective methodology for sustainable rehabilitation projects (Brandt, personal communication, Sept. 25, 2016).

MTBA's interpretation of Collections is a reflection of the evolution of how OSCAR integrates the concept of "Whole Building Ecology." This generated insightful discussions about how OSCAR 2.0 could better express the complex interrelationships between buildings, systems and components.

\subsection{Next Steps}

The next step is to develop OSCAR version 2.0 into a robust and fully functional application with a substantial quantity of content in each of the databases. This will allow more comprehensive testing by a broader user base.

The results of the research so far demonstrate that it is both feasible and desirable to further develop OSCAR as an educational resource and decision-making aid, to help improve sustainable performance of existing buildings while maintaining heritage character and values.

\section{ACKNOWLEDGEMENTS}

OSCAR is an initiative lead by author Cory Rouillard of APTI's TC-SP and is the result of the hard work of many volunteers within APTI including the APTI Executive \& Board, OSCAR Advisory Committee, Co-Chairs of the Technical Committee on Sustainable Preservation, OSCAR peer reviewers, and the OSCAR research and development team. Many thanks to Professor Mario Santana Quintero, his students, MTBA Associates, Inc. and the Ottawa East Seventh Day Adventist Church for assistance with the case studies. The OSCAR Committee is grateful for the generous support of: the National Center for Preservation Technology and Training (NCPTT); Mitacs Canada; the Historic Preservation Education Foundation (HPEF); Natural Sciences and Engineering Research Council of Canada (NSERC); and Create Heritage Engineering (Carleton University). Furthermore, we thank Mike Ludlum of Useful Solutions and Katrina Ambrose (UX designer) for their technical expertise in creating the web applications.

\section{REFERENCES}

Architecture 2030. "2030 Palette: Design and Planning Strategies for the Next Built Environment, Today", http://2030palette.org/ (9 Jun. 2017).

Association for Preservation Technology International. "OSCAR: Inherently Sustainable Features", http://oscarapti.org/glossary/inherently-sustainable-features/ (9 Jun. 2017).

\section{Preservation,"}

\section{"Technical Committee on Sustainable} http://www.apti.org/clientuploads/Technical\%20Committees/20 13\%20APT\%20Brochure\%208\%205\%20x\%2011\%20CC_2013 -10-03.pdf. 
Federal Provincial Territorial Historic Places Collaboration, 2016. Building Resilience: Practical Guidelines for the Sustainable Rehabilitation of Buildings in Canada. Library and Archives Canada, Ottawa.

Historic England, 2009. "Research into the Thermal Performance of Traditional Windows: Timber Sash Windows", https://content.historicengland.org.uk/images-

books/publications/thermal-performance-traditional-

windows/thermal-performance-traditional-windows.pdf/.

May 2017)

InspectAPedia, 2017. "About InspectAPedia.com", http://inspectapedia.com/Admin/About_InspectApedia.php. (1 Jun. 2017).

Powter, A., and Ross, S., 2005. Integrating Environmental and Cultural Sustainability for Heritage Properties. APT Bulletin, 36(4), pp. 5-11.

Sustainable Traditional Buildings Alliance. "Guidance Wheel", United Kingdom http://www.responsible-retrofit.org/wheel/ (1 Jun. 2017).

, 2012. "Responsible Retrofit of Traditional Buildings", http://www.ihbc.org.uk/recent_papers/docs/STBAresponsible_r etrofit2012.pdf. (1 Jun. 2017). 